\title{
An Efficient Preclean of Aluminized Silicon Substrate for Chemical Vapor Deposition of Submicron Tungsten Plugs
}

\author{
Wen-Kuan Yeh, Ming-Hsing Tsai, Sheng- Hsiung Chen, and Mao-Chieh Chen* \\ Department of Electronics Engineering, National Chiao Tung University and National Nano Device Laboratory, \\ Hsinchu, Taiwan
}

Pei-Jan Wang, Lu-Min Liu, and Mou-Shiung Lin

Taiwan Semiconductor Manufacturing Company, Hsinchu, Taiwan

\begin{abstract}
Preclean of aluminum trench and via patterned substrates is vital for successful selective chemical vapor deposition of tungsten (CVD-W). A convenient preclean method uses in situ $\mathrm{BCl}_{3}$ plasma etching to remove the native metal oxide prior to conducting the CVD-W. During the plasma etching, however, the outsputtered aluminum oxide and aluminum can be redeposited on the sidewall of the trench and via hole and on the surface of the dielectric layer, where $W$ nucleation is induced, resulting in creep-up and selectivity loss during tungsten deposition. By using a solution of hydroxylamine sulfate to pretreat the aluminum trench and via hole patterned substrates, we successfully avoid the creep-up and selectivity loss of W deposition.
\end{abstract}

\section{Introduction}

Via filling by selective chemically vapor deposited tungsten (selective CVD-W) has been proposed to overcome the difficulty of achieving conformal step-coverage with sputtered metal deposition into via holes of high aspect ratio, ${ }^{1-2}$ and to improve the planarity of metallization systems. ${ }^{3}$ Effective control of deposition selectivity is important for selective CVD-W. The first difficulty which occurs, especially with silane-reduced selective CVD-W, is the local loss of selectivity called "creep-up." Creep-up is the phenomenon where tungsten growth starts not only from the bottom but also from the sidewall of a via hole. Creep-up can cause such problems as void formation in the plug or shorts between via holes. A possible reason for creep-up is that, during the via etching, polymer is formed on the sidewall of the via hole. ${ }^{5}$ Heavy metals of less than $0.5 \mathrm{ppm}$ contained in the commercially available positive photoresists cause contamination during the resist stripping by direct $\mathrm{O}_{2}$ plasma exposure. ${ }^{6}$ The inorganic metallic contamination in a form of metallic oxides becomes the nucleation sites for tungsten on the sidewall of the via. ${ }^{7}$ Since the CVD reaction runs in a depletion mode that enhances deposition at the via mouth, unwanted void formation is likely. ${ }^{4}$

Another possible cause of creep-up is the in situ plasma etching, which is used to remove the metal oxide from the aluminum surface prior to $\mathrm{W}$ deposition. During the plasma etching, the sputtered aluminum oxide and aluminum can be redeposited on the sidewall of the via and on the surface of the dielectric layer, resulting in creep-up and selectivity loss during subsequent selective CVD-W. Thus, appropriate precleans are necessary for achieving good selectivity. We investigated the effect of plasma etching on the selective deposition of $\mathrm{W}$ for $\mathrm{W}$ plug formation. We

* Electrochemical Society Active Member. found that a hydroxylamine sulfate solution is capable of removing the insoluble metal oxide around the bottom of the via leading to improvement of selectivity.

\section{Experimental}

Aluminum alloy (Al-1\%Si-0.5\% Cu) was sputter-deposited on thermally oxidized silicon wafers to a thickness of $5000 \AA$. We also sputter-deposited a $400 \AA$ antireflection layer (ARL) of TiN over the aluminum layer as the final step of a multistep metal deposition process. This assists in forming well-resolved, fine line resist images that are free of "necking" and "notching." The sample with TiN/ AlSiCu bilayer was patterned by reactive ion etching (RIE) and subsequently covered, in sequence, with dielectric layers of $2000 \AA$ plasma-enhanced chemical vapor deposited (PECVD) oxide, $3000 \AA$ spin-on-glass (SOG), and $5000 \AA$ PECVD oxide. Via holes ranging from 0.6 to $1.2 \mu \mathrm{m}$ were patterned using the conventional photolithographic and dry etching technique. The $400 \AA$ TiN layer which would have increased the via resistance was removed during the RIE of the via hole. Trenches with widths ranging from 0.6 to $1.2 \mu \mathrm{m}$ were also defined and patterned by RIE. The etching process must overetch the aluminum layer to eliminate stringers and low volatility etch products of additives such as copper. ${ }^{8}$

Prior to selective CVD-W processing, the wafers were treated with various precleans. A group of wafers were dipped in dilute solutions of hydroxylamine sulfate $\left[\left(\mathrm{NH}_{2} \mathrm{OH}\right)_{2} \cdot \mathrm{H}_{2} \mathrm{SO}_{4}\right]$ with a concentration of $0.1 \mathrm{M}$ for 30 to $480 \mathrm{~s}$ at a temperature of $40-60^{\circ} \mathrm{C}$. In situ ultrasonic agitation was used. The wafers were loaded into the load-locked cold wall CVD-W system within 5 min after dipping in the hydroxylamine sulfate solution. A second group of wafers were treated with various in situ $\mathrm{BCl}_{3}$ plasma etching conditions in the CVD system. The predeposition plasma etch-

Table I. Selective CVD-W on submicron trenches and via holes with various precleans.

\begin{tabular}{|c|c|c|c|c|c|}
\hline \multicolumn{2}{|c|}{ Predeposition treatment } & \multicolumn{4}{|c|}{ Selective CVD-W } \\
\hline \multirow{2}{*}{$\begin{array}{l}\text { Hydroxy-sulfate } \\
\text { wet etching } \\
\text { (temp/time) }\end{array}$} & \multirow{2}{*}{$\begin{array}{l}\mathrm{BCl}_{3} \text { plasma } \\
\text { etching } \\
\text { (power/time) }\end{array}$} & \multicolumn{2}{|c|}{$\begin{array}{l}\text { W filling in trench } \\
\left(250^{\circ} \mathrm{C} / 120 \mathrm{~s}\right)\end{array}$} & \multicolumn{2}{|c|}{$\begin{array}{l}\text { W filling in via hole } \\
\left(250^{\circ} \mathrm{C} / 180 \mathrm{~s}\right)\end{array}$} \\
\hline & & Results & Selectivity & Results & Selectivity \\
\hline - & - & $\begin{array}{l}\text { A few } W \text { islands } \\
\text { (Fig. 1a) }\end{array}$ & - & $\begin{array}{l}\text { No deposition } \\
\text { (Fig. 2a) }\end{array}$ & - \\
\hline- & $50 \mathrm{~W} / 60 \mathrm{~s}$ & $\begin{array}{l}\text { Creep-up } \\
\text { (Fig. 1b) }\end{array}$ & Selectivity loss & $\begin{array}{l}\text { No deposition } \\
\text { (Fig. 2b) }\end{array}$ & Blanket \\
\hline $60^{\circ} \mathrm{C} / 90 \mathrm{~s}$ & - & $\begin{array}{l}\text { Good } \\
\text { (Fig. 1c) }\end{array}$ & Good & $\begin{array}{l}\text { Good } \\
\text { (Fig. 2c) }\end{array}$ & Good \\
\hline $60^{\circ} \mathrm{C} / 90 \mathrm{~s}$ & $50 \mathrm{~W} / 60 \mathrm{~s}$ & $\begin{array}{l}\text { Creep-up } \\
\text { (Fig. 1d) }\end{array}$ & Selectivity loss & $\begin{array}{l}\text { Creep-up } \\
\text { (Fig. 2d) }\end{array}$ & Blanket \\
\hline
\end{tabular}



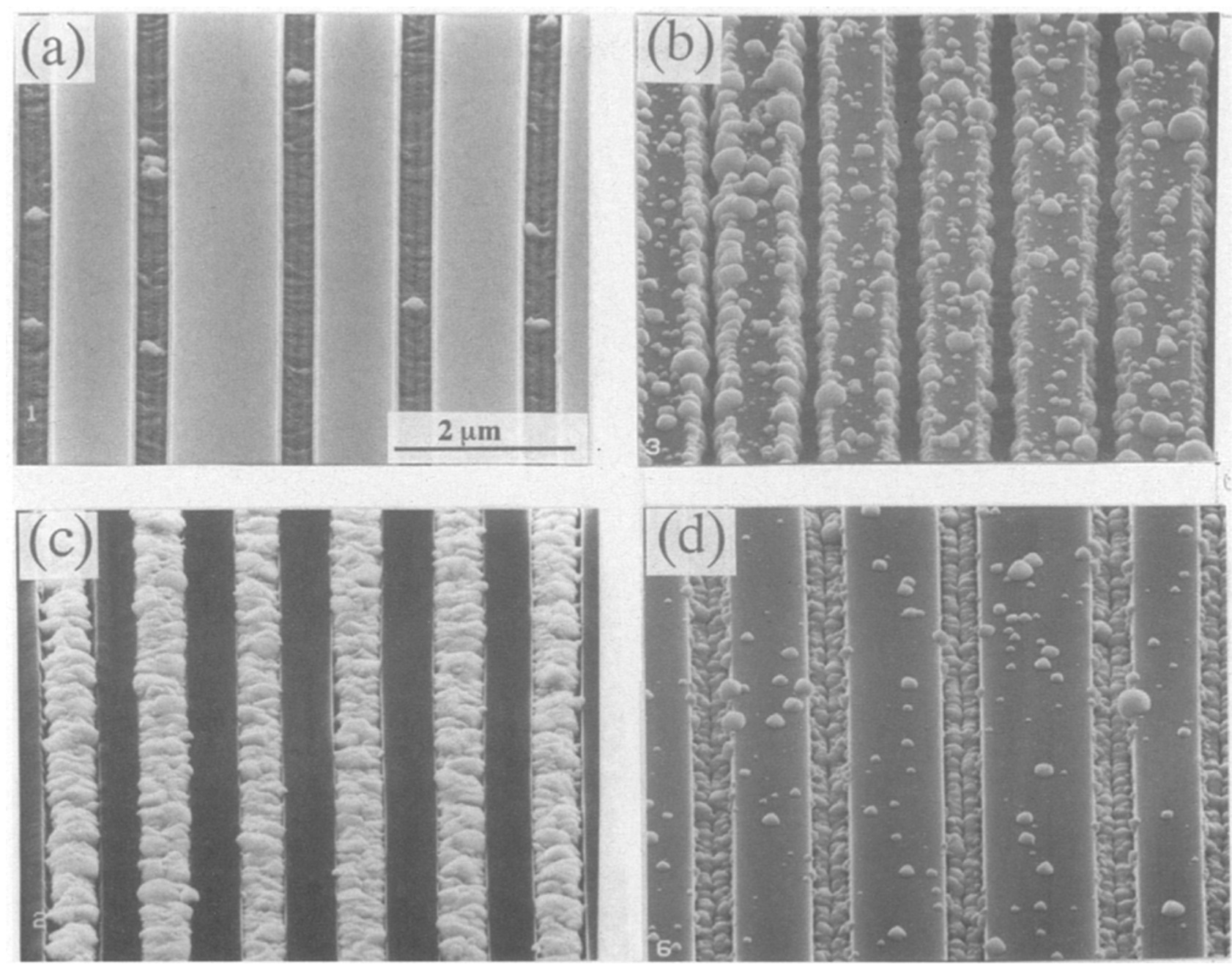

Fig. 1. Top view SEM micrographs showing selective CVD-W in submicron trenches with various precleans of substrate: (a) without any precleaning; (b) with $50 \mathrm{~W} \mathrm{BCl}_{3}$ plasma etching; (c) with hydroxylamine sulfate wet etching; and (d) with wet etching of (c) followed by plasma eiching of (b).

ing was conducted with a radio frequency $(\mathrm{RF})$ power of 0 to $100 \mathrm{~W}, \mathrm{~B} \mathrm{BCl}_{3}$ flow rate of $100 \mathrm{sccm}$, and a chamber pressure of 6 mTorr. A post-plasma-etch annealing at $370^{\circ} \mathrm{C}$ for $180 \mathrm{~s}$ was performed to eliminate such by-products as $\mathrm{AlCl}_{3}$ from the aluminum surface. The wafers were then transferred from the plasma etching chamber to the deposition chamber without exposure to atmosphere. The base pressure of the CVD chamber was $10^{-6}$ Torr. Typical conditions for the selective $\mathrm{CVD}-\mathrm{W}$ in this work were as follows: substrate temperature $250^{\circ} \mathrm{C}$, total gas pressure $6 \mathrm{mTorr}$, $\mathrm{WF}_{6}$ flow rate $20 \mathrm{sccm}$, and $\mathrm{SiH}_{4}$ flow rate $10 \mathrm{sccm}$.

The thickness of the $\mathrm{W}$ plugs was determined by scanning electron microscopy (SEM). Via resistance was measured using the four-terminal Kelvin structure prepared by the conventional very large scale integrated (VLSI) processing where the via holes were $0.6 \mu \mathrm{m}$ deep and 1.2 to $5 \mu \mathrm{m}$ in diameter.

\section{Results and Discussion}

Trench patterns.- Selective $\mathrm{W}$ deposition in submicron trenches with aluminum at the bottom with various precleans was investigated; the results are summarized in Table I. Without any preclean, $W$ cannot be deposited easily on the aluminum surface because the aluminum oxide retards the nucleation of $\mathrm{W}$; thus, only a few $\mathrm{W}$ islands were deposited, as shown in Fig. 1a. With a $50 \mathrm{~W} \mathrm{BCl}_{3}$ plasma etching for $60 \mathrm{~s}$, creep-up and selectivity loss of $\mathrm{W}$ deposition was observed, as shown in Fig. 1b. This is believed to be due to the outsputtered aluminum oxide and aluminum induced $\mathrm{W}$ nucleation on the sidewalls of trenches and the surface of the dielectric layer. The selectivity loss becomes worse with prolonged deposition (e.g., $180 \mathrm{~s}$ or longer).
Plasma etching with higher power resulted in more severe creep-up deposition and selectivity loss. When the wafers were treated with $\mathrm{BCl}_{3}$ without turning on the $\mathrm{RF}$ power to generate a plasma, it was hard to deposit $\mathrm{W}$ on the aluminum. Apparently, the aluminum oxide in the trench cannot be removed by $\mathrm{BCl}_{3}$ alone.

The selectivity of CVD-W can be improved significantly by precleaning the substrate wafer in a hydroxylamine sulfate solution, which is presumably capable of completely removing the aluminum oxide in the submicron aluminum trench. After the hydroxylamine sulfate wet etching, excellent selective $\mathrm{W}$ deposition on the submicron aluminum trench can be obtained, as shown in Fig. 1c. No selectivity loss or creep-up of $\mathrm{W}$ was found. To investigate the effect of $\mathrm{BCl}_{3}$ plasma treatment, a wafer that had been etched in the solution of hydroxylamine sulfate was loaded into a plasma chamber for a $\mathrm{BCl}_{3}$ plasma etching prior to conducting the CVD-W. After wet etching and low power $(50 \mathrm{~W})$ plasma etching, selective deposition of $\mathrm{W}$ in the aluminum trench can be obtained, as shown in Fig. 1d. Creep-up and selectivity loss of $W$ deposition were observed, apparently because aluminum particles were outsputtered by the $\mathrm{BCl}_{3}$ plasma. It is clear from the above observation that the plasma etching induces the creep-up and selectivity loss during $\mathrm{W}$ deposition.

Via patterns.-Selective $\mathrm{W}$ deposition on submicron via holes down to Al with various precleans was investigated, and the results are summarized in Table 1 . Compared to the selective $W$ filling of trenches, it is more difficult to control the selectivity loss for the $\mathrm{W}$ filling of via holes. Without a preclean, $W$ did not nucleate in the submicron via, as 

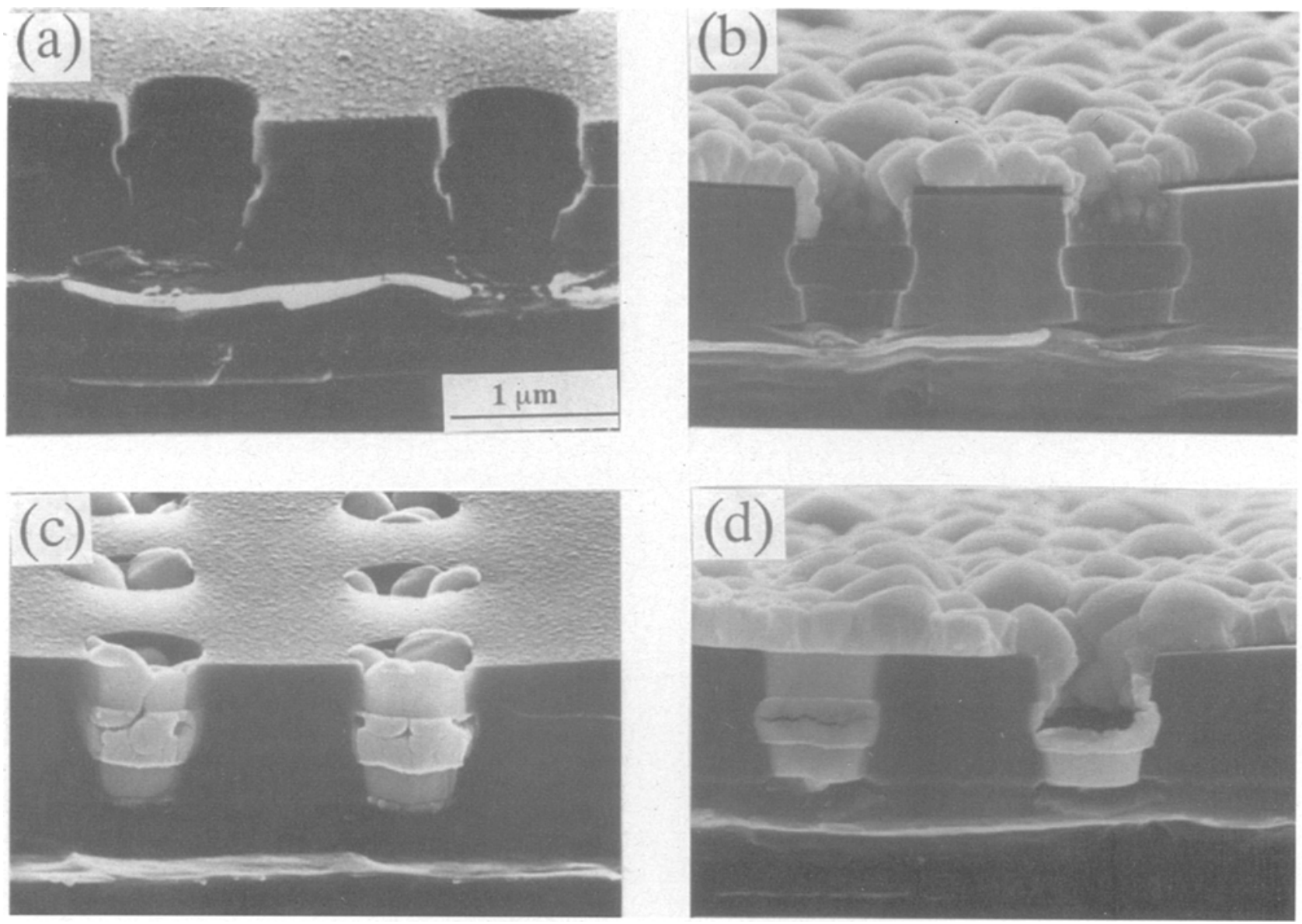

Fig. 2. Cross-sectional SEM micrographs showing CVD-W in submicron via holes with various precleans of substrate: (a) without any precleaning, (b) with $50 \mathrm{~W} \mathrm{BCl}_{3}$ plasma elching; (c) with hydroxylamine sulfate wet etching; and (d) with wet etching of (c) followed by plasma etching of (b).

shown in Fig. 2a. The belly-shaped via is due to the different etching rate between SOG and PECVD oxide during the via etching. With a $50 \mathrm{~W} \mathrm{BCl}$ plasma treatment for 60 $\mathrm{s}$, blanket $\mathrm{W}$ deposition was obtained with practically no deposition of $W$ in the via hole, as shown in Fig. $2 \mathrm{~b}$. This is different from the trench result (Fig. 1b) where a larger aluminum surface is exposed. On the substrate containing via holes, plasma-generated aluminum particles induced $W$ nucleation first on the surface of $\mathrm{SiO}_{2}$ and around the via mouths, whereas no deposition of $\mathrm{W}$ inside the via hole was possible. To clarify the cause of selectivity loss, a blanket oxide-covered wafer was loaded into the CVD-W system for an in situ $\mathrm{BCl}_{3}$ plasma cleaning followed by CVD-W deposition. No deposition of $W$ on the oxide surface was observed. This indicates that the loss of selectivity is not due to possible damage of the oxide by the plasma. The selectivity loss presumably is due to outsputtered aluminum particles.

Precleaning the wafer in a solution of hydroxylamine sulfate significantly improved the selectivity of CVD-W and resulted in a full $\mathrm{W}$ filling on via holes, as shown in Fig. 2c. When the preclean was followed by a low power (50 W) plasma etching prior to conducting the CVD-W, the CVD-W resulted in creep-up and blanket deposition of $W$, as shown in Fig. 2d. From the above observation, it is clear that the aluminum oxide in the submicron via was removed sufficiently to allow $\mathrm{W}$ nucleation by the hydroxylamine sulfate solution, but the subsequent plasma etching presumbly outsputtered the aluminum particles and had them redeposited on the surface of $\mathrm{SiO}_{2}$. For the wet clean in the solution of hydroxylamine sulfate, it was found that the optimum condition is to wet etch at $60^{\circ} \mathrm{C}$ for $90 \mathrm{~s}$. In situ ultrasonic agitation is necessary for completely cleaning the submicron via as well as to ensure a uniform $W$ deposition. Low resistivity $(\sim 13 \mu \Omega-\mathrm{cm})$ tungsten film was selec- tively deposited on $0.6 \mu \mathrm{m}$ vias with a deposition rate of $330 \mathrm{~nm} / \mathrm{min}$. At the beginning of $\mathrm{W}$ deposition, $W$ was nucleated from the bottom of submicron via holes, as shown in Fig. 3a, leading to many large islands. These islands merge together, finally resulting in the $W$ plug with a rough surface, as shown in Fig. 3b. Figure 3c shows a cross-sectional micrograph of $W$ plug with a smooth W/AISiCu interface.

Chemical characterization.-Hydroxylamine sulfate $\left[\left(\mathrm{NH}_{2} \mathrm{OH}\right)_{2} \cdot \mathrm{H}_{2} \mathrm{SO}_{4}\right]$ is a powerful reducing agent capable of removing aluminum oxide $\left(\mathrm{Al}_{2} \mathrm{O}_{3}\right)$. We proposed the overall process as follows. Since hydroxylamine $\left(\mathrm{NH}_{2} \mathrm{OH}\right)$ may be thought of as being derived from $\mathrm{NH}_{3}$ by the replacement of one hydrogen by $\mathrm{OH}$, it is a weaker base than $\mathrm{NH}_{3}$ and can be easily dissolved in water ${ }^{9}$

$$
\mathrm{NH}_{2} \mathrm{OH}_{(\mathrm{aq})}+\mathrm{H}_{2} \mathrm{O} \rightarrow \mathrm{NH}_{3} \mathrm{OH}^{+}+\mathrm{OH}^{-}
$$

When the aluminum via patterned wafer is immersed in the solution of hydroxylamine sulfate, the aluminum oxide $\left(\mathrm{Al}_{2} \mathrm{O}_{3}\right)$ and/or aluminum at the bottom of the via hole undergoes the following reaction ${ }^{10}$

$$
\mathrm{Al} \text {, or } \mathrm{Al}_{2} \mathrm{O}_{3}+\mathrm{OH}^{-} \rightarrow \mathrm{Al}(\mathrm{OH})_{3}(\mathrm{~s})
$$

Thus, the hydroxylamine sulfate solution with the concentration of $0.1 \mathrm{M}$ etches the aluminum to some extent. The aluminum consumption is dependent on the temperature and concentration of the solution. Figure 4 shows aluminum consumption $v s$. etching time in a solution of hydroxylamine sulfate with the concentration of $0.1 \mathrm{M}$ at two different ambient temperatures. About $45 \mathrm{~nm}$ of Al was removed by $60 \mathrm{~s}$ of etching at $60^{\circ} \mathrm{C}$. The reaction by-product $\mathrm{Al}(\mathrm{OH})_{3(s)}$ was precipitated in a hydrated form as a white gelatinous mass that is soluble in acid ${ }^{11}$ 


$$
\mathrm{Al}(\mathrm{OH})_{3(\mathrm{~s})}+3 \mathrm{H}^{+} \rightarrow \mathrm{Al}^{3+}(\mathrm{aq})+3 \mathrm{H}_{2} \mathrm{O}(\mathrm{l})
$$

where the $\mathrm{H}^{+}$ion was contributed by $\mathrm{H}_{2} \mathrm{SO}_{4}$ in the hydroxylamine sulfate solution. In this way, the native aluminum oxide can be completely removed by the hydroxylamine sulfate solution. The deionized water rinse is necessary for removing the by-products of this reducing reaction.

Electrical and physical characterization.-Via resistance was measured using a four-terminal Kelvin structure of $\mathrm{AlSiCu} / \mathrm{W} / \mathrm{AlSiCu}$. Figure 5 illustrates the measured via resistance $v s$. via size for two different etching treatments
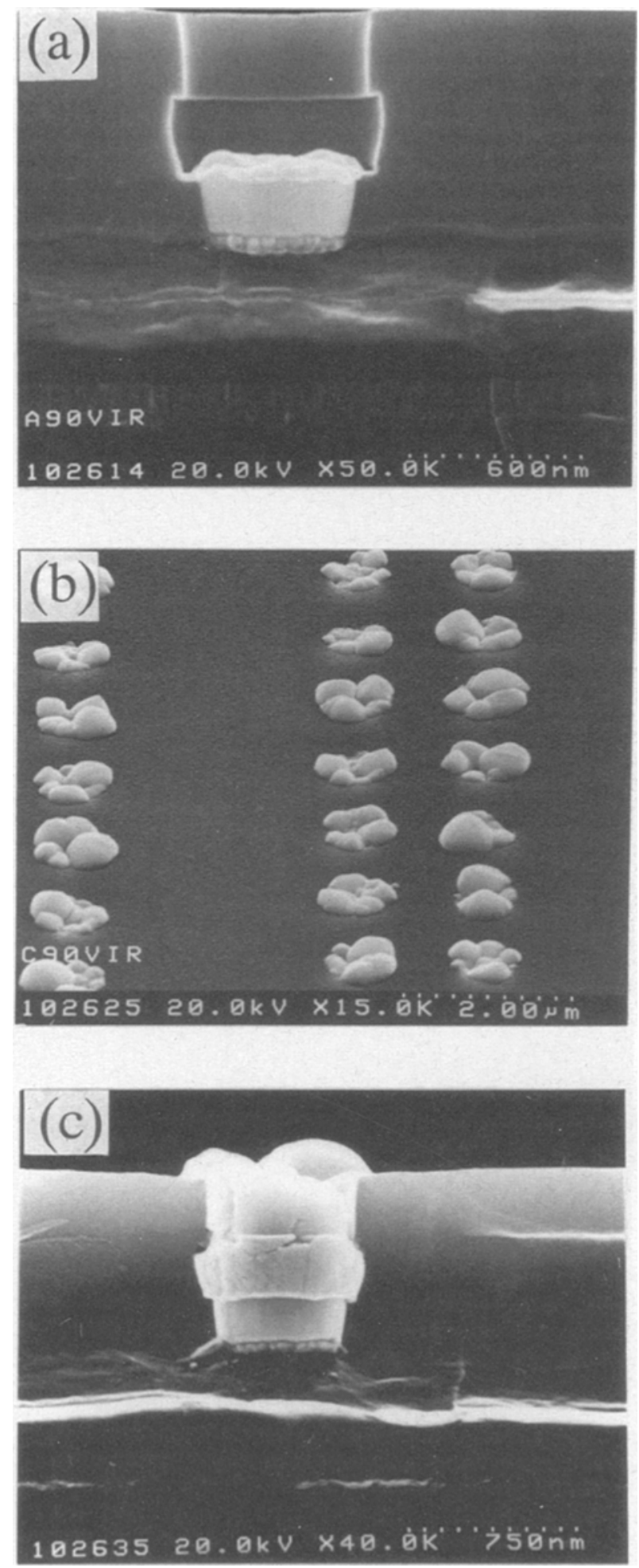

Fig. 3. (a) Cross section, (b) top view, and (c) cross-sectional SEM micrographs showing CVD-W filling in submicron via pretreated with hydroxylamine sulfate wet etching.

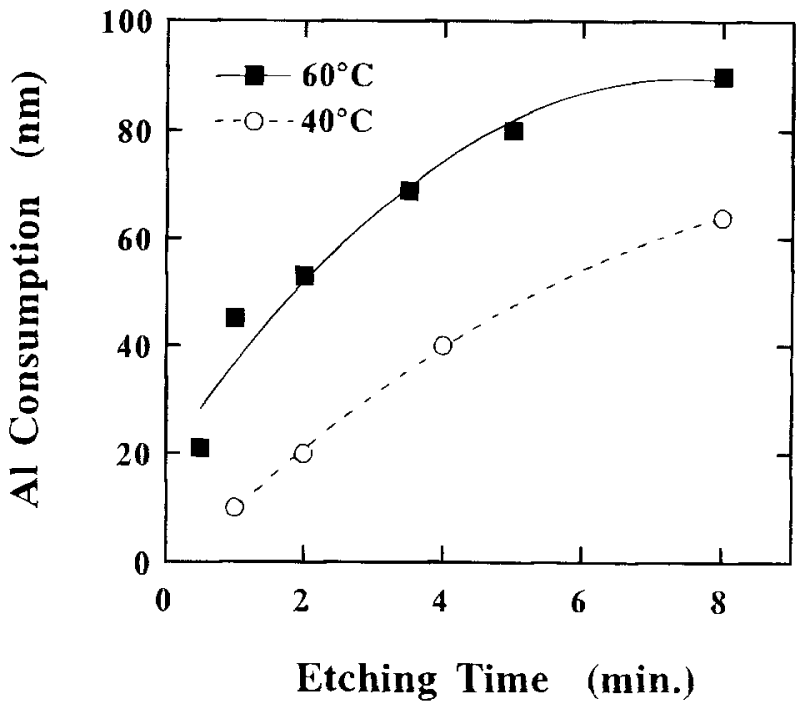

Fig. 4. Aluminum consumption vs. etching time of hydroxylamine sulfate solution at temperatures of 40 and $60^{\circ} \mathrm{C}$.

prior to CVD-W. At least 20 randomly chosen samples were measured in each case. The slightly higher via resistance for the sample treated with the hydroxylamine sulfate wet etching presumably is due to the reoxidation of the aluminum surface during the short time when the sample was exposed to the air before loading into the $\mathrm{W}$ deposition chamber.

Comparison was made on secondary ion mass spectroscopic (SIMS) depth profiles measured on CVD-W deposited on the aluminum substrate with and without precleans. Without precleaning, the depth profile of high aluminum and oxygen concentration in the surface region, as shown in Fig. 6a, indicates the presence of aluminum oxide; apparently no $\mathrm{W}$ film was deposited on the aluminum. It can be seen from Fig. $6 \mathrm{~b}$ that the aluminum oxide was removed and a $\mathrm{W}$ film was deposited on the sample with $30 \mathrm{~W} \mathrm{BCl}_{3}$ plasma etching. Similar results were obtained for the sample precleaned with the hydroxylamine sulfate solution, as shown in Fig. 6c. The high concentration of fluorine at the aluminum/tungsten interface is presumably due to the $\mathrm{AlF}_{3}$ compound that is formed during CVD-W. ${ }^{12,13}$ At the same deposition time of CVD-W, comparsion between Fig. $6 \mathrm{~b}$ and $\mathrm{c}$ indicates that a thicker $\mathrm{W}$ film was deposited on the substrate that was precleaned using $\mathrm{BCl}_{3}$ plasma etching; this presumably is due to the

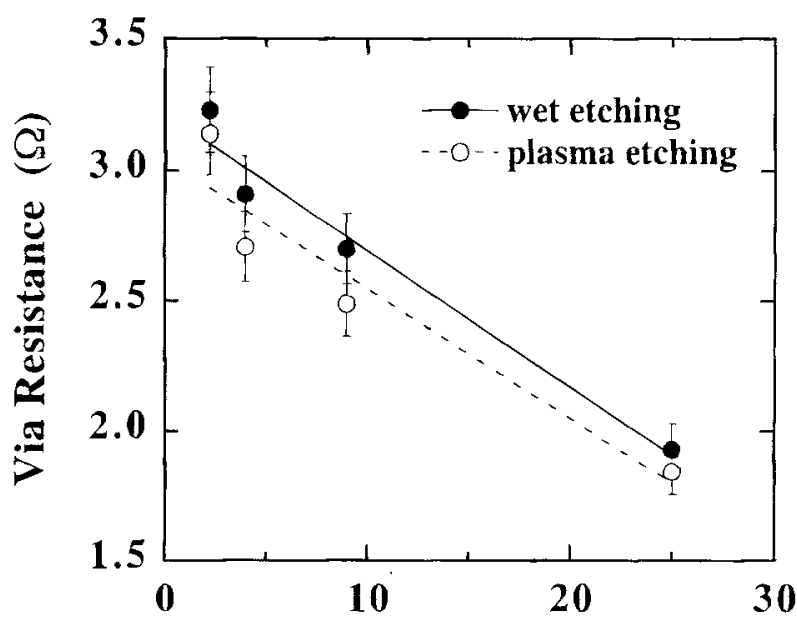

\section{Via Size $\left(u m^{2}\right)$}

Fig. 5. Via resistance vs. via size with precleans of $50 \mathrm{~W} \mathrm{BCl}_{3}$ plasma etching and hydroxylamine sulfate wet etching. 

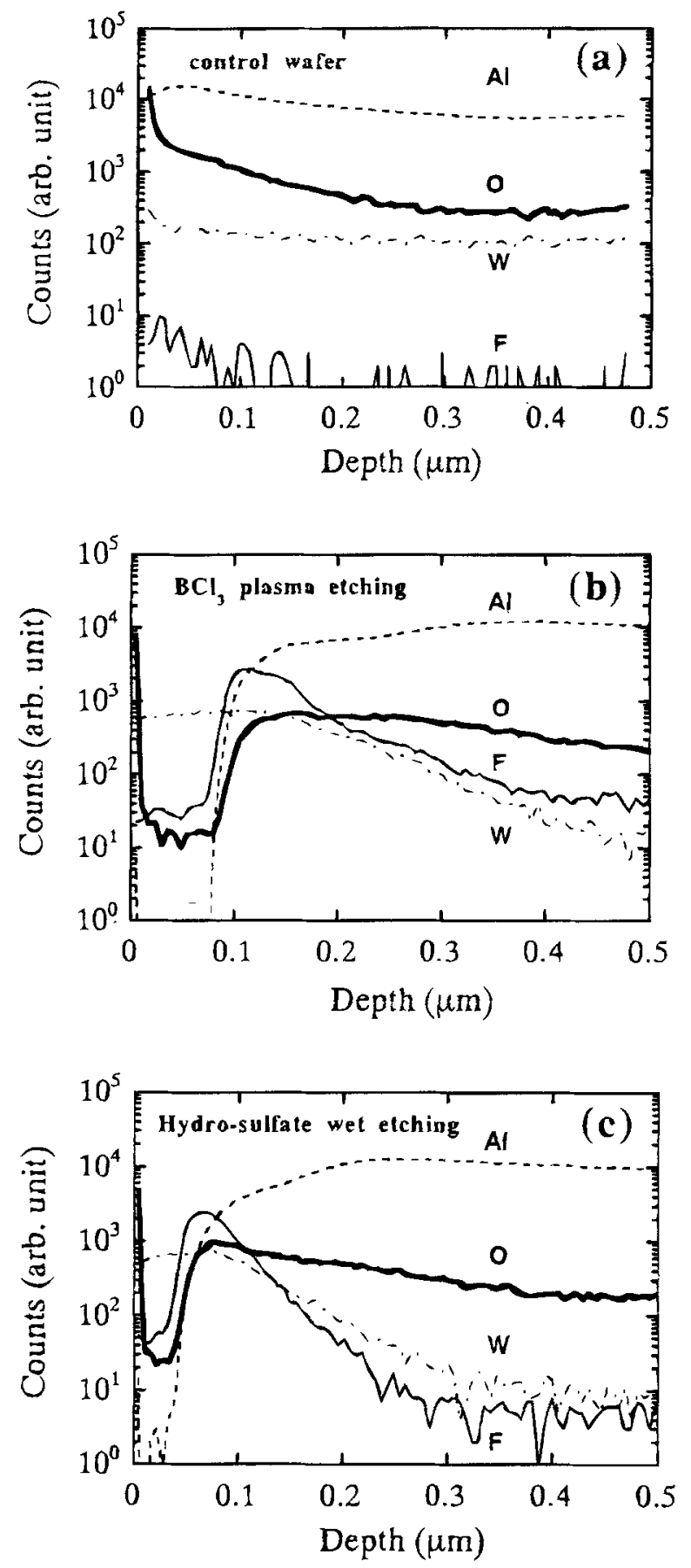

Fig. 6. SIMS depth profiles of $60 \mathrm{~s}$ CVD-W deposition on aluminum substrates (a) without any precleaning; (b) with $30 \mathrm{~W} \mathrm{BCl}_{3}$ plasma etching; and (c) with dilute hydroxylamine sulfate wet etching. plasma-generated surface damage on $\mathrm{Al}$, which can easily induce $\mathrm{W}$ nucleation on the damaged sites.

\section{Conclusion}

Precleaning of the aluminum trench and via patterned substrate is vital to the successful selective CVD-W. As to $\mathrm{BCl}_{3}$ plasma etching precleaning, we found that the outsputtered aluminum oxide and/or aluminum can be redeposited on the sidewall of the trench and via hole, as well as on the surface of the $\mathrm{SiO}_{2}$. This resulted in creep-up and selectivity loss during the subsequent selective CVD-W. Excellent selective CVD-W can be obtained using the hydroxylamine sulfate solution to pretreat the trench and via patterned substrate; this precleaning completely removes the metal oxide at the bottom of aluminum trench and via. Thus, creep-up and selectivity loss of $\mathrm{W}$ deposition can be avoided.

\section{Acknowledgment}

This work was supported by the National Science Council (ROC) under Contract No. NSC84-2622-E009-007-1.

Manuscript submitted March 14, 1995; revised manuscript received June 6, 1995.

National Chiao Tung University assisted in meeting the publication costs of this article.

\section{REFERENCES}

1. R. H. Wilison, R. W. Stall, and M. A. Calacone, VLSI Multilevel Interconnection Conference, IEEE, p. 343, New York (1985).

2. D. M. Brown, B. Horowitz, P. Piacente, R. Sara, R. Wilson, and D. Woodruff, IEEE Electron Device Lett., EDL-8, 55 (1987).

3. C. Kaanta, W. Cote, J. Cronin, K. Holland, P. l. Lee, and T. Wright, IEEE IEDM, Tech. Digest, 218 (1987).

4. J. E. J. Schmitz, Chemical Vapor Deposition of Tungsten and Tungsten Silicide, pp. 75-80, Noyes Publications, Park Ridge, NJ (1992).

5. D. L. Flamm, Solid State Technol., 37 (August, 1992).

6. S. Fujimura and H. Yano, This Journal, 135, 1195 (1988).

7. D. R. Broadbury, J. E. Turner, K. Nauka, and K. Y. Chiu, IEEE IEDM Tech. Digest, 273 (1991).

8. P. E. Riley, S. S. Peng, and L. Fang, Solid State Technol., 47 (Feb. 1993).

9. F. A. Cotton and G. Wilkinson, Advanced Inorganic Chemistry, pp. 319-320, John Wiley \& Sons, New York (1988).

10. F. A. Cotton and G. Wilkinson, Basic Inorganic Chemistry, pp. 313-314, John Wiley \& Sons, New York (1987).

11. G. I. Brown, Introduction to Inorganic Chemistry, pp. 194-195, Longman-Greene, London (1985).

12. M. L. Yu, K. Y. Ahn, and R. V. Joshi, J. Appl. Phys., 67, $1055(1990)$

13. H. Ohsima, M. Katayama, K. Onoa, and T. Hatori, This Journal, 140, 801 (1993). 